\title{
Mode and storage load based control of a complex building sys- tem with a geothermal field
}

Gerrit Bode, Johannes Fütterer, Dirk Müller

This document is the pre-print of an article published in Energy and Buildings (158) pp. 13371345 (DOI: 10.1016/j.enbuild.2017.11.026).This document is published under Creative Commons BY-NC-ND license (https://creativecommons.org/licenses/by-nc-nd/4.0/).

Please cite this article as:

Gerrit Bode, Johannes Fütterer, Dirk Müller, Mode and storage load based control of a complex building system with a geothermal field, Energy and Buildings, Volume 158, 2018, Pages 13371345, ISSN 0378-7788, https://doi.org/10.1016/j.enbuild.2017.11.026.

Our open-source projects are available at https://github.com/RWTH-EBC

\author{
RWTH Aachen University \\ E.ON Energy Research Center
}

Institute for Energy Efficient Buildings and Indoor Climate (EBC)

Mathieustrasse 10, D-52074 Aachen

$\mathrm{T}+4924180-49760, \mathrm{~F}+4924180-49769$,

post_ebc@eonerc.rwth-aachen.de,www.eonerc.rwth-aachen.de/ebc 


\title{
Mode and storage load based control of a complex building system with a geothermal field
}

\author{
Gerrit Bode, Johannes Fütterer, Dirk Müller
}

\begin{abstract}
The development of control strategies is a challenge for optimal use of lowtemperature heat in complex energy systems. In the energy system of the considered building several different combinations of active system components lend themselves to supply a given energy demand. Within preceding research, we transformed the considered building into a multi-functional test bench for control techniques that offers optimal conditions for the demonstration and evaluation of control strategies. This paper describes a control strategy for the complex heat pump system based on operation modes. It enables us to integrate a geothermal field into the system with respect to exergetic principles. The paper presents results of the control strategy's first year of operation. It correlates between active operation modes and the respective electrical consumption of the building. We derive the potential of the implemented operation modes for demand response applications. A modebased control strategy enables the robust and efficient operation of complex building-energy-systems. We show that the integration of renewable energy sources becomes easy and flexible.
\end{abstract}

Keywords: heat pump, geothermal field, control, control strategies, heat pump control, building control strategies, demand response, building automation, building control

\section{Introduction}

With rising requirements for energy efficiency building energy systems become more complex. Apart from renewable energy sources and combined heat and power plants, heat pump systems with different heat sources and

Email address: gbode@eonerc.rwth-aachen.de (Gerrit Bode) 
heat sinks play an important part. The combination of these systems with complex energy conversion systems is able to fulfil a building's energy demand using different operation strategies. To ensure the energy efficient operation of a building equipped in such systems, complex control strategies are required.

In this paper, we present a mode-based control as a new strategy for complex building energy systems. We demonstrate the use of a storageload-based strategy a tool for the selection of operation modes based on the actual building load. The functionality of this tool is validated with building data. The mode-based control facilitates the flexible integration of renewable energies. The buildings are further prepared to provide services to the user or the grid, e.g. Dual Demand Site Management [1], if production is available, or at least Demand Response. Therefore the need for complex and expensive control strategy development is reduced and the effective operation of complex energy systems is facilitated.

In the next chapter, we first describe the general problem that occurred in the use case building. Then we will present the method for developing a mode-based control strategy. We then abstract this method to make it applicable to a general construction process. In chapter 4, we present a way to use the method to integrate renewable energy sources into the control at the example of a geothermal field. Chapter 5 presents a case study, during which the method was developed. The resulting control strategy and the load-based control is presented in chapter 6 . In chapter 7 we discuss the measurement results of the actual operation. The impact of the operation modes on the electric demand of the building is discussed in chapter 7.1. We conclude the paper with a prospect on further research topics.

\section{Problem}

In common cases, heat pump systems used for heating are controlled via the condenser outlet temperature, or, if used for cooling, via the outlet temperature of the evaporator. A heat pump used for providing both heating and cooling is referred to as integrated heat pump. If used in an energy efficient manner, an integrated heat pump can satisfy both heat and cooling demands in a building at the same time. Heat pump vendors do in general not provide control algorithms for this task. The main objective of the heat pump is the supply of a temperature potential in both cold and warm water storages. Since heat and cold production are linked in an integrated heat 
pump, additional heat sources or sinks have to be considered with regard to overall energy balance. For example, excess heat can be dissipated in a glycol cooler to maintain the cold storage temperature or heat can be extracted from a geothermal field.

During the construction phase the design and realization of our building automation system was not done in a centralized, coordinated and iterative effort but according to the planers design across all systems. This resulted in a non-functional system. Main cause was the decentralized control of all subsystems. A switch between heating and cooling modes was guided exclusively by the ambient temperature. This did not represent the real demand of the building and let to contradicting operation of systems, e.g. producing heat with a boiler and cooling the heat network with the glycol cooler at the same time.

The biggest challenge was the identification of a control strategy for the whole system and especially for the heat pump system, so that the vendorimplemented switch between heating and cooling mode of the heat pump is considered and additional heat sinks and sources are used accordingly. After that, we had to implement rules as to when a certain operation mode should be used. We included the balanced use of the geothermal field over the course of a year in these considerations.

\section{Related Work}

Heat pumps in combination with geothermal fields for heat supply or displacement have been on the rise for several years and are widely used all over the world [2] [3] [4]. Efforts have been made to specifically design heat pump systems for integrated use, thus improving the overall energy efficiency of the system [5]. To offset differences in the heating and cooling demand, ground-coupled heat pump systems have been combined with other equipment for heat supply or displacement.

Several operating strategies for geothermal heat pump systems have been modelled using simulated and real building data [6] [7] [8]. However, implementation of these concepts into real buildings requires significant domain knowledge and a high detailed knowledge of the building system and its operational state.

Ground-coupled heat pump systems either extract heat from the ground to be used for heating applications or displace heat to the ground when used 
in cooling applications. This results in a change of the ground temperature and therefore reduced heat transfer rates and worse performance of the system [3] [9] [10]. To prevent this, a balanced heat in- and output of the geothermal field is needed.

\section{Method}

The following chapter covers the control strategy development method applied by us to the E.ON ERC main building at RWTH Aachen and the resulting proposal of an idealized process applicable to any building in the design stage. The emphasis of the proposed method is the classification of the operation in distinct operation modes and the method of determining which mode should be used. As operation mode we generally understand a certain operational state of a building system, e.g. "On", "Off", "Heat", "Cool", "Humidify" etc. In a stricter sense, we can define operation mode as a combination of system components specially designed for a certain case, e.g. "Cooling using the heat pump, the geothermal field and the glycol cooler" (see Chapter 6.1). To determine between the global modes "Heating" or "Cooling", we propose a heuristic approach to determine the real building load using the storage potential of the heat pumps storage system without necessitating additional sensors (see Chapter 6.2).

\subsection{Control strategy development process}

Figure 1 shows the actual process as it took place during control strategy development at the E.ON ERC. Beginning with the initial building operation, a monitoring system was installed in the building [2]. The measurement data was recorded. In a parallel effort, the sub-systems of the building, especially the heat pump, the condensing boiler and the heat output of both concrete core activation system and façade ventilation units, was modelled and then simulated in Modelica. For simulating behaviour of the geothermal field SHEMAT was used [11].

Using the recorded measurement data, we were able to validate and improve the simulation models. The data of the subsystems and the overall system was evaluated and detailed analysis of the measurement data was conducted [12]. From this we derived further information on the system behavior. The next step was to develop a list of all possible load cases and a rough estimate of their yearly occurrence. On the other hand, all rational combinations of the system components were defined as operation modes. 


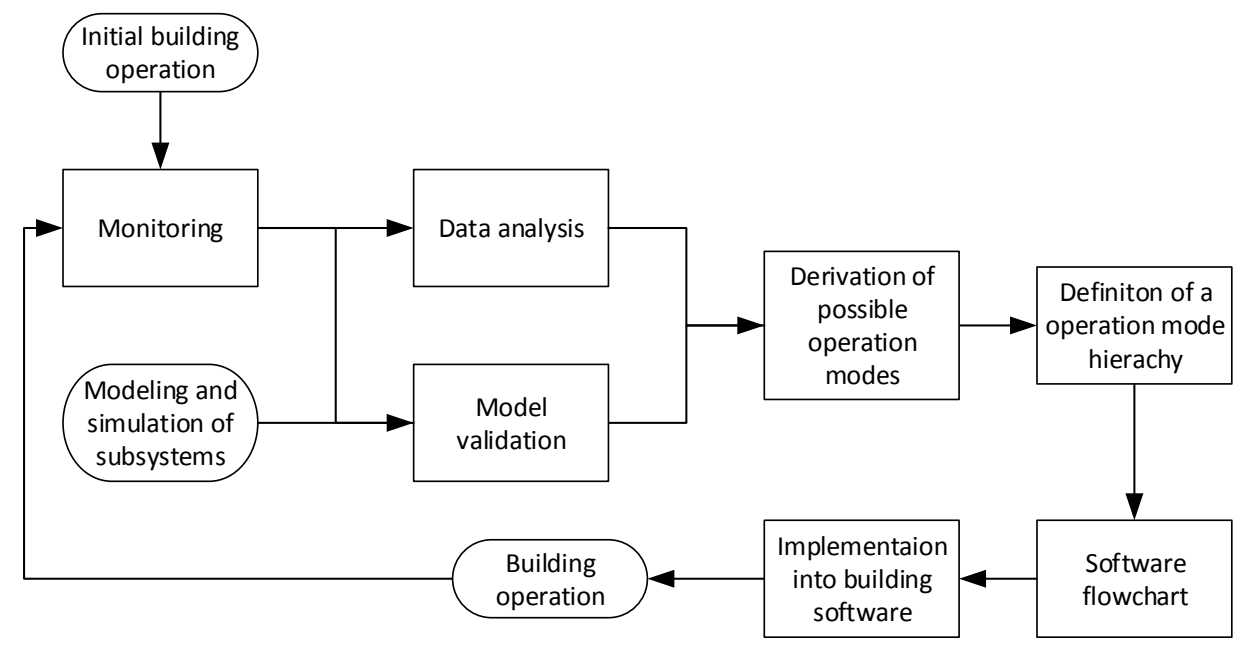

Figure 1: Process of the control strategy development at the E.ON ERC

Based on considerations about the exergetic efficiency we derived a hierarchy and then matched the operation modes with the load situations. An estimate of the frequency of occurrence for each operation mode was made by comparing the hierarchy to all possible ambient situations over the course of a year (see table 4.1 for an example from January to March). Heat demand is determined by radiation as well as ambient temperature. For each combination of load and ambient conditions a suitable operation mode was selected. A detailed software flow chart was designed as an unambiguous combination of the control diagram, i.e. the description of all sensors and actuators in the building, and the function description written in plain text. This flow chart facilitated the implementation of the developed control strategy by the building automation vendor. This implementation was closely assisted and the operation of the implemented strategy was analyzed in detail. Daily, automatized analysis of the operation and the continuous analysis of the recorded and current measurement data ensured its quality.

\subsection{Ideal mode-based control strategy development process}

We propose the process shown in figure 2 as an idealized concept for developing a control strategy during the building process.

1. Based on the concept of the building and the energy system all possible 


\begin{tabular}{|c|c|c|c|c|c|c|c|}
\hline Month & $\begin{array}{l}\text { Time } \\
\text { of day }\end{array}$ & $\operatorname{Air} \mathrm{T}^{1}$ & Weather & GTF $\mathrm{T}^{2}$ & $\begin{array}{l}\text { Heat de- } \\
\text { mand }\end{array}$ & $\begin{array}{l}\text { Cooling } \\
\text { demand }\end{array}$ & $\begin{array}{l}\text { Operation } \\
\text { mode }\end{array}$ \\
\hline January & $\begin{array}{l}\text { Night } \\
\text { Day }\end{array}$ & $\begin{array}{r}-12^{\circ} \mathrm{C} \\
-5{ }^{\circ} \mathrm{C} \\
1{ }^{\circ} \mathrm{C}\end{array}$ & $\begin{array}{l}- \\
\text { cloudy } \\
\text { sunny }\end{array}$ & $12^{\circ} \mathrm{C}$ & $\begin{array}{l}\text { highest } \\
\text { very high } \\
\text { high }\end{array}$ & low & Heating \\
\hline February & $\begin{array}{l}\text { Night } \\
\text { Day }\end{array}$ & $\begin{array}{r}-10^{\circ} \mathrm{C} \\
-2{ }^{\circ} \mathrm{C} \\
3{ }^{\circ} \mathrm{C}\end{array}$ & $\begin{array}{l}\text { - } \\
\text { cloudy } \\
\text { sunny }\end{array}$ & $10^{\circ} \mathrm{C}$ & $\begin{array}{l}\text { very high } \\
\text { moderate } \\
\text { low }\end{array}$ & low & Heating \\
\hline March & $\begin{array}{l}\text { Night } \\
\text { Day }\end{array}$ & $\begin{array}{r}2^{\circ} \mathrm{C} \\
6{ }^{\circ} \mathrm{C} \\
10^{\circ} \mathrm{C}\end{array}$ & $\begin{array}{l}\text { - } \\
\text { cloudy } \\
\text { sunny }\end{array}$ & $9^{\circ} \mathrm{C}$ & $\begin{array}{l}\text { high } \\
\text { moderate } \\
\text { very low }\end{array}$ & $\begin{array}{l}\text { low } \\
\text { low } \\
\text { moderate }\end{array}$ & $\begin{array}{l}\text { Heating } \\
\text { Cooling }\end{array}$ \\
\hline
\end{tabular}

Table 1: Extract of the qualitative yearly development of the ambient condition

load situations for the energy distribution are collected. Following Table 1 the specific demands of the building are assessed using the likely ambient conditions for each month of the year. Components with behavior that is altered of the course of a year, e.g. geothermal fields, should be included in the analysis. All theoretically possible combinations of working subsystems are listed as operation modes in a matrix.

2. Load cases and operation modes are combined on the basis of theoretical considerations.

3. The resulting combination of load cases and operation modes can be assessed and ranked either by simulation or theoretically using a selectable cost function (e.g. fuel costs, primary energy consumption, renewable energy integration etc.).

4. Operation modes are sorted in a hierarchy, which defines the order in which they are selected in a given load case.

5. Conditions are derived from the hierarchy as to when the current operation mode has to change. These conditions need to be well described in order to develop a control software that is to be implemented within the building.

\subsection{Integration of renewable energies into the built environment}

With the proposed control strategy, introduced operation modes can be actively chosen or the switching conditions can be slightly varied according

\footnotetext{
${ }^{1}$ Outside air temperature

${ }^{2}$ Geothermal field outlet temperature
} 


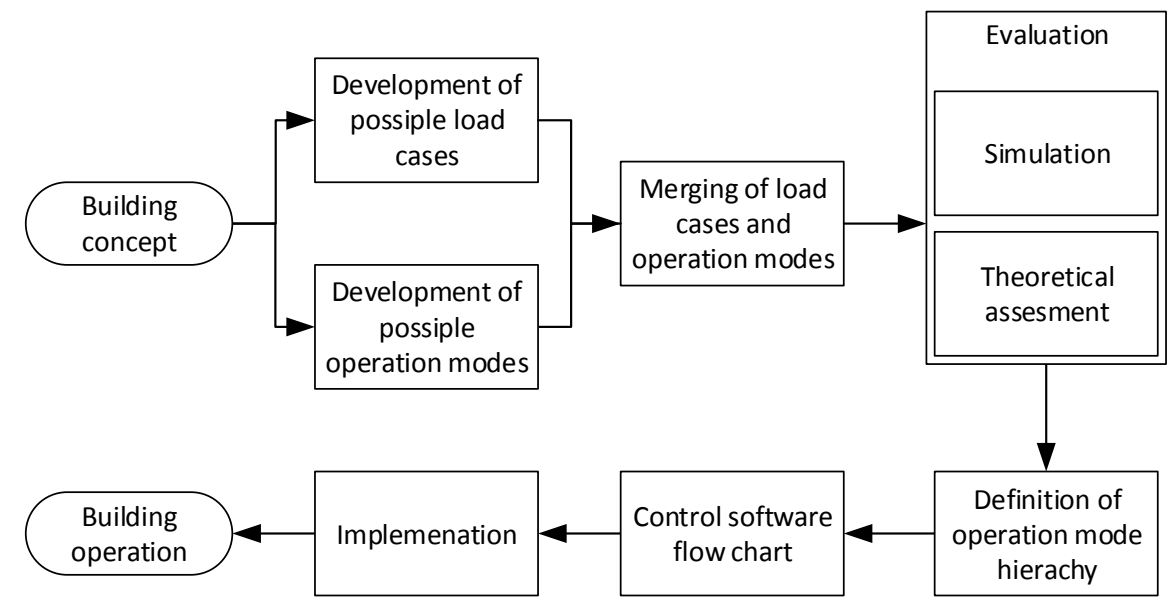

Figure 2: Proposal for an idealized control strategy development

to e.g. the load, power production by renewable energy, or external signals. In the case of the buildings geothermal field, a balanced operation can be archived in an iterative process. The annual energy balance of the field is calculated. If it is not zero, certain operation modes can be blocked or the switching conditions can be adapted. The process is planned to be supported by simulations in the future.

\section{Case study}

The main building of the E.ON Energy Research Center at the RWTH Aachen is a multi-purpose building with by a variety of different users. This results in a hard to predict demand of heating, cooling and ventilation. Hot and cold water are needed on different temperature level due to the use in air conditioning and laboratory tasks. The building includes small and large scale offices, server rooms, laboratories and workshops as well as seminar and conference rooms. Due to the building size, user behavior and ambient conditions constitute an individual demand profile for every room. To account for this special demand structure, an innovative energy concept was developed for the building. Criteria were the thermal comfort and the minimization of fossil resource consumption. Water at four temperature levels is used to fulfil the demand of each room type. 
1. Cooling for laboratory processes at $6{ }^{\circ} \mathrm{C}$

2. Cooling for thermal comfort at $17^{\circ} \mathrm{C}$

3. Heating for thermal comfort at $35^{\circ} \mathrm{C}$ (Low temperature grid)

4. Heating for laboratory processes at $80^{\circ} \mathrm{C}$ (High temperature grid)

The energy concept is structured into three layers: the energy demand, the energy conversion and the energy distribution. The structure with the integrated devices is shown in Figure 3.

The low temperature demand is covered by a turbo-compressor heat pump with variable-speed centrifugal compression with magnetic, oil-free bearings, providing a high efficiency in wide areas of partial load, which at the same time provides the cold water at $12{ }^{\circ} \mathrm{C}$. Waste heat from server and LAN rooms serves as energy source for the heat pump. Additionally, a geothermal field with 40 boreholes can be used for heating and cooling, depending on the outlet temperature. A glycol cooler serves as cooling mechanism when ambient temperatures are low. High temperature heat is provided in the energy conversion layer using a combined heat and power engine (CHP). For peak loads or CHP failures two condensing boilers are available. High temperature heat can be used to transfer heat to the low temperature grid using a heat exchanger to support or back-up the heat pump system.

The heating or cooling energy is delivered to the office and conference rooms using a concrete core activation system. A sorption supported process precools the fresh air supply to $21^{\circ} \mathrm{C}$ if ambient temperatures are too high. Peaks in demand are covered by façade ventilation and displacement ventilation units. Laboratories can be cooled with active chilled beams and air cooling devices.

A comprehensive monitoring system was installed to evaluate the performance of the system. A central database logs the changes in energy flows, physical state variables and ambient conditions as well as all changes in input and output signals, network variables and control parameters. The data storage is event-based, meaning that values are saved only when a changes surpasses a set threshold. The monitoring system allows concluding operation characteristics for subsystems and a detailed analysis of switching operations and control strategies. Several interface systems allow easy communication with the automation systems turning the building into an effective test bench and demonstrator for new control strategies. 


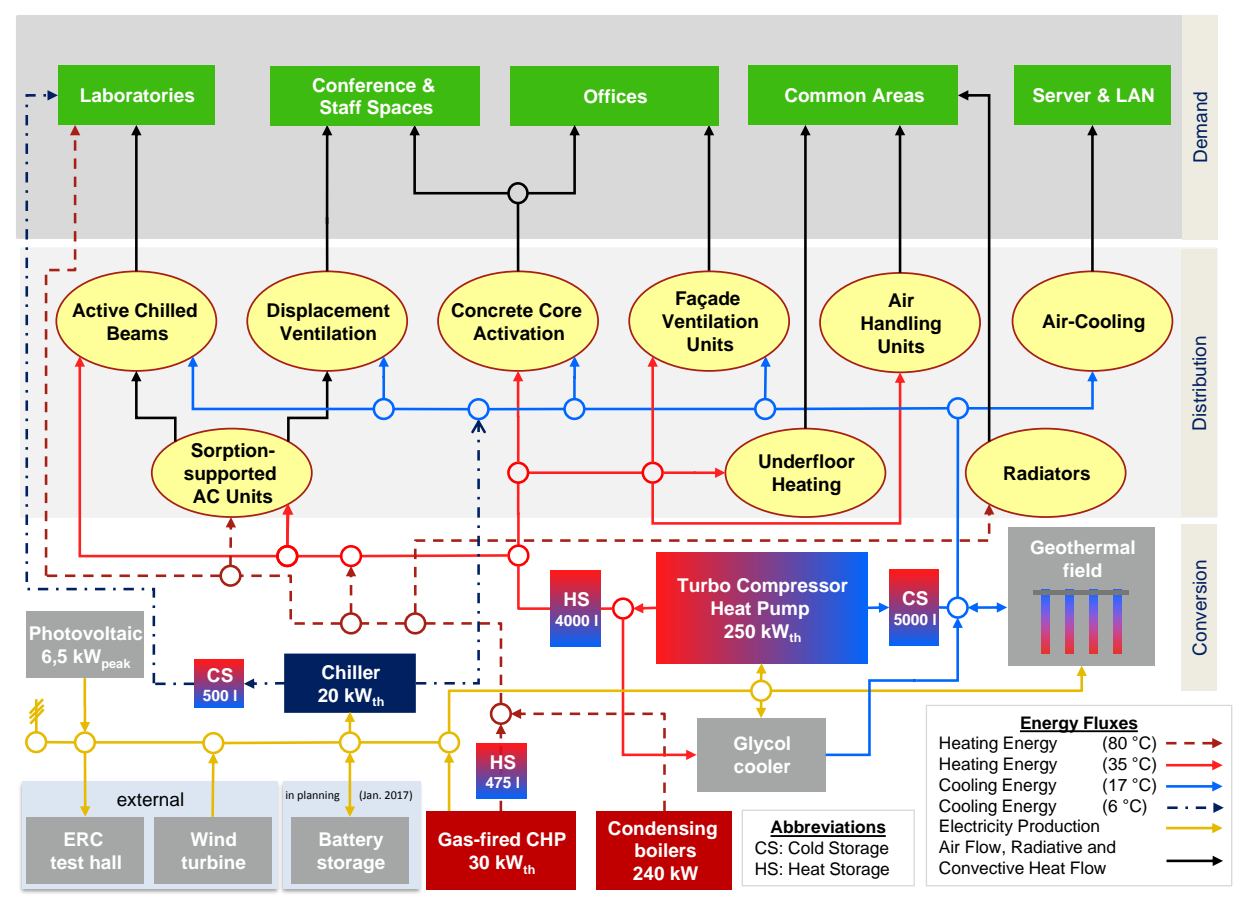

Figure 3: The energy system of the E.ON ERC at the RWTH Aachen 


\subsection{Heat pump}

The heat pump is the integral part of both coolant and low temperature grid. It is connected to the flow and return lines of the system. Storage systems decouple the operation of the heat pump from the actual demand, allowing for intermittent operation for demands below the minimal power of the heat pump. The heat pump can be either controlled with the outlet temperature of the condenser in a range of $30^{\circ} \mathrm{C}$ and $50{ }^{\circ} \mathrm{C}$, which leads to a control based on the heat demand, or with the outlet temperature of the evaporator in $6{ }^{\circ} \mathrm{C}$ to $15^{\circ} \mathrm{C}$ range leading to a cold demand based control. The actual control of the heat pump system is proprietary and can only be modified in limited manner.

\subsection{Geothermal field}

The geothermal field consists of 40 boreholes with a depth of $100 \mathrm{~m}$ each. The closed circuit is operated by two feed pumps. The circuit is connected to the cooling grid with a heat exchanger. The geothermal field can be used for either providing heat to the cooling circuit return, which provides more energy to the heat pump and thus increase heating efficiency, or to remove heat from the cooling circuit and store it in the ground, reducing cooling demand at the heat pump. Given low enough ground temperatures, the geothermal field can be used for cooling the entire building by itself. Ground temperature is depended on the season and the overall use of the geothermal field. Excessive use can lead to overheating or undercooling the geothermal field resulting in too high or too low outlet temperatures respectively and therefore rendering it unusable for either storing or extracting more heat.

\subsection{Glycol cooler}

A glycol cooler is connected to the low temperature and cooling grids. The ventilation system can dissipate heat into the environment. If ambient temperatures are low enough, the glycol cooler can directly cool the cooling grid. This is further referred to as free cooling (fc). If the heat pump is used for cooling, surplus heat in the low temperature grid is created. Especially during times of low demand, this heat can be removed with the glycol cooler to prevent rising temperatures in the low temperature grid. The heat pump also works more efficient when the temperature difference between hot and cold site is low. This mode of operation for the glycol cooler is further referred to as recooling (rc). 


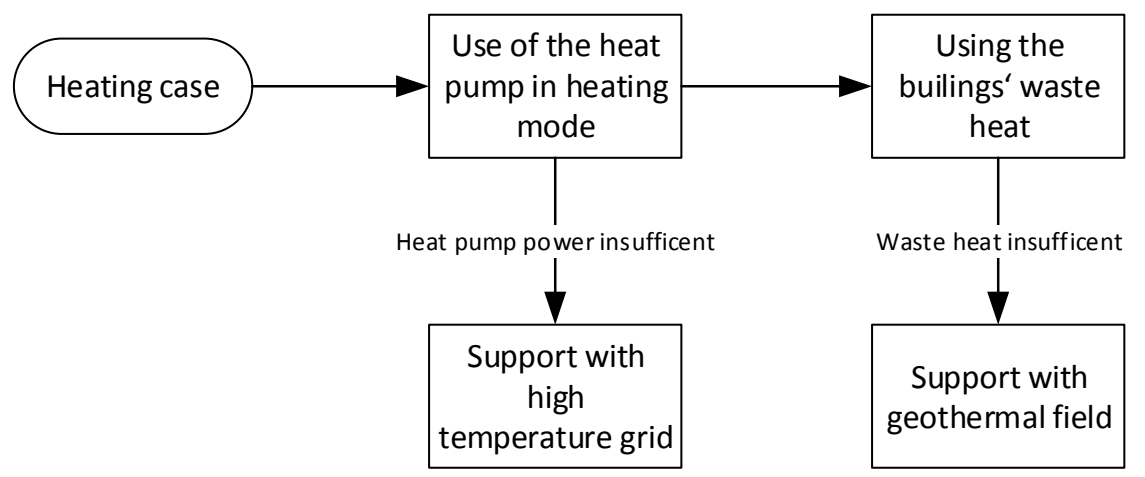

Figure 4: Operation modes for the heating case

\section{Developed control strategy}

The method presented in Chapter 4 was applied to the energy system presented in Chapter 5 considering the most important subsystems. The resulting operation mode hierarchy consists of two main operation modes, heating and cooling, and several subordinate operation modes. To decide between the main operation modes a storage-load-based control is used.

\subsection{Operation modes}

For the heating case three useful operation modes can be identified with theoretical assessments (see Figure 4). Similarly, we identified six operation modes for the cooling case (see Figure 5). If there is a heat demand in the building, it will be covered by the heat storage. This results in a decreasing temperature in the heat storage. The heat pump will then transfer waste energy from the building into the low temperature heat grid. If the waste heat is insufficient, i.e. the temperature in the cooling storage drops below a certain point, heat will be drawn from the geothermal field to support the heat pump. If the heat pump cannot supply the buildings demand, i.e. the set-point flow temperature in the low temperature grid cannot be achieved, additional heat is provided by the CHP or condensing boilers and transferred from the high temperature to the low temperature grid.

The integration of the geothermal field into the cooling case operation modes was done with regard to exergetic optimizations. For this the operational hysteresis and limits in the energy transfers were considered, the 


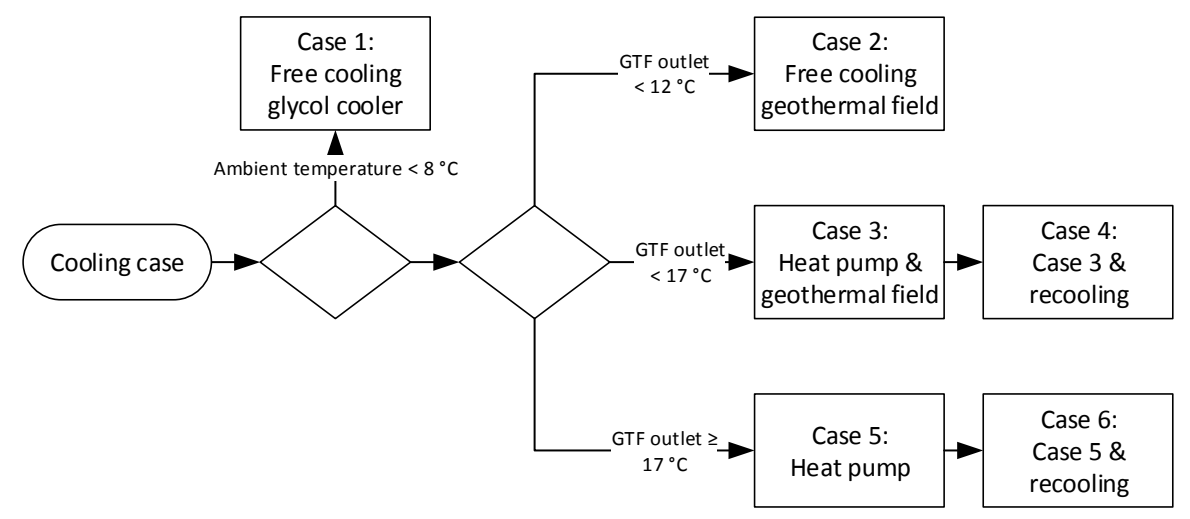

Figure 5: Operation modes for the cooling case

energy needed for the feed pumps and auxiliary energies were disregarded. This lead to the following hierarchy in cooling operation modes:

1. Free cooling using the glycol cooler

2. Free cooling using the geothermal field

3. Heat pump operation with geothermal support

4. Heat pump operation with geothermal support and recooling via the glycol cooler

5. Heat pump operation

6. Heat pump operation with recooling via the glycol cooler

If the ambient temperature is below $8^{\circ} \mathrm{C}$, the temperature spread at the glycol cooler is high enough to satisfy the cooling demand using only the free cooling by the glycol cooler (case 1). If ambient temperatures are too high, but geothermal outlet temperatures are low, the building can be cooled using the geothermal field (case 2). If the geothermal outlet temperature is above $12{ }^{\circ} \mathrm{C}$, the heat pump is used to produce cooling energy, while the geothermal field is used for $17^{\circ} \mathrm{C}$ cooling applications (case 3). If there is no sufficient heat demand, the glycol cooler is used to dissipate excess heat (case 4). If the geothermal field is no longer available, the heat pump covers the whole demand (case 5), if necessary with the use of recooling (case 6). If the system is in cooling mode, but there is also a heat demand, case 5 will be used periodically to ensure the storage temperature in the low temperature heating grid is maintained. 


\subsection{Storage-load-based control}

The top-level decision is to be made between heating and cooling case. It makes sense to use the actual building load situation, rather than, for example, outside temperatures. To determine the load situation, each temperature levels load has to be measured. Another option is the forecast with simulation models. To provide the needed information with only the typically installed sensors and without the use of error-prone models we propose the use of a storage-load-based control approach.

Previous iterations of the building control strategy have shown that the use of ambient temperatures as indicator for the building load does not lead to a usable control. This can be explained by the highly dynamic, complex overall systems, user behavior, high isolation, inert systems like the geothermal field as well as other reason. Instead, the decision on the main operation mode should be made based on the energy flows in the building. For this, change of the temperature in the hot and cold storages of the heat pump system is very well suited. To avoid distortion of the result by the heat pump, this assessment shall only be made when the heat pump is off. The result is a cyclic assessment of the demand, that shall be occur after every stop of the heat pump. The heat pump usually stops if its lower power minimum is reached, it will then continue in intermittent operation.

To calculate an energy potential $(P)$ for each storage we use the average storage temperature $(T)$, using four measurement points, the storage volume $(V)$ and the isobar heat capacity of the water $\left(c_{p}\right)$. If the potential for the heat storage is sinking faster than the cold storage potential, a higher heat demand is assumed in relation to the cold demand; and vice versa. To assess the temporal change of the storage potential we use a sampling rate $(\Delta t)$ of 300 second. We calculate the gradient of the storage potential as difference of storage potential of two time steps. According to a threshold value, the decision for either heating or cooling case is made. In a first trial, the threshold value is zero. If the heat capacity is considered equal for water of the given temperatures and the sample rate is constant, the considerations can be expressed in the following simplified equations:

$$
\begin{gathered}
P_{\text {Storage }}=\bar{T}_{\text {Storage }} \cdot V_{\text {Storage }} \\
\Delta P_{\text {Storage }}=P_{\text {Storage }}(t)-P_{\text {Storage }}(t+\Delta t)
\end{gathered}
$$




\subsection{Integration of the geothermal field}

For an optimal use over several years, the geothermal field needs to be operated in a balanced manner to avoid overheating or overcooling the ground. To achieve this, the following approaches are proposed:

- Variation of the switching condition between geothermal cooling and geothermal cooling with heat pump support. Raising this temperature will increase the heat input into the field and vice versa.

- Temporal deactivation of all geothermal-supported operation modes. The transferred energy will be reduced.

- Increasing the heat transferred from the high temperature grid will reduce the need to supply the waste heat with the geothermal field, thus reducing the energy removed from the ground.

\section{Results and Discussion}

The E.ON ERC main building is equipped is an extensive monitoring system which allows detailed evaluation of the building operation [13]. Figure 6 shows a frequency distribution of the operation modes from the 1st July 2014 up to the 1st July 2015, grouped by ambient temperature interval. For reasons of readability, there is no distinction between the heating cases in this figure. The frequency of each mode changes with the ambient temperature. When the system is off, the energy in the storages is used to supply the building.

In the temperature ranges over $29^{\circ} \mathrm{C}$, most of the time the building is using cooling operation case 4 (heat pump operation with geothermal support and recooling). If the ambient temperature falls into the range between $21^{\circ} \mathrm{C}$ and $29^{\circ} \mathrm{C}$, the share of case 4 sinks, while case 3 gets more prominent in the intervals between $13{ }^{\circ} \mathrm{C}$ and $23^{\circ} \mathrm{C}$. Cases 5 and 6 have low shares, because they are lower in hierarchy and only used once the geothermal field is heated up. In the intermittent temperature range there is a mixture of all operation modes, with a high share of system downtime. These combinations represent an active heat displacement by the heat pump in intermittent operation. If the temperature sinks below the freezing point, the most prominent cases are naturally the heating operation modes, while the intermittent operation continues until the mean building load is higher than the minimal heat pump power, so that the heat pump can switch to continuous operation. 


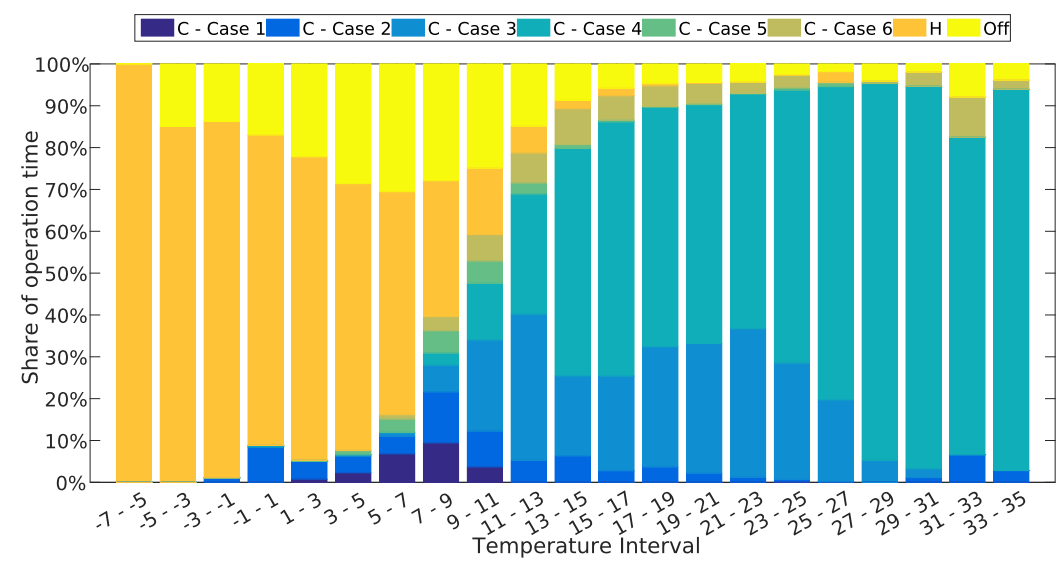

Figure 6: Frequency of the operation modes versus ambient temperature

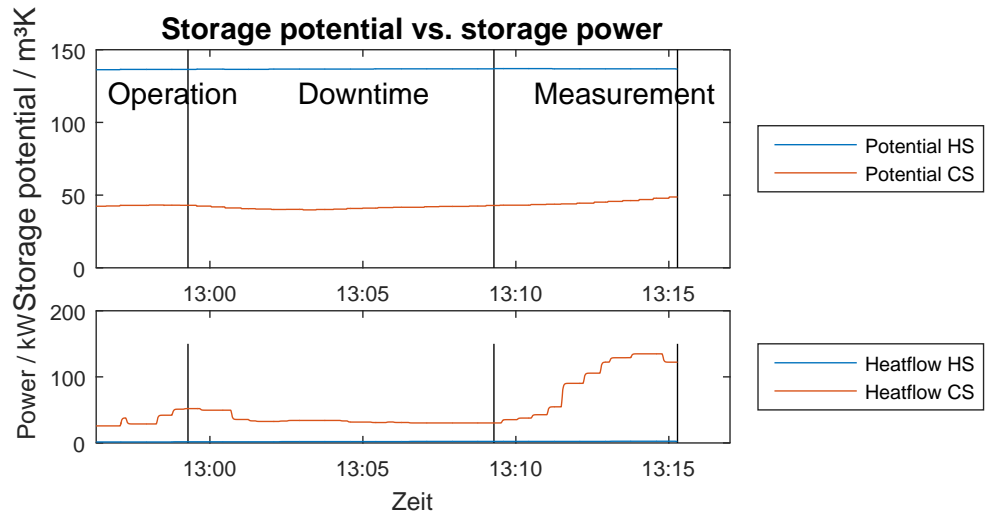

Figure 7: Storage potential vs. storage power 


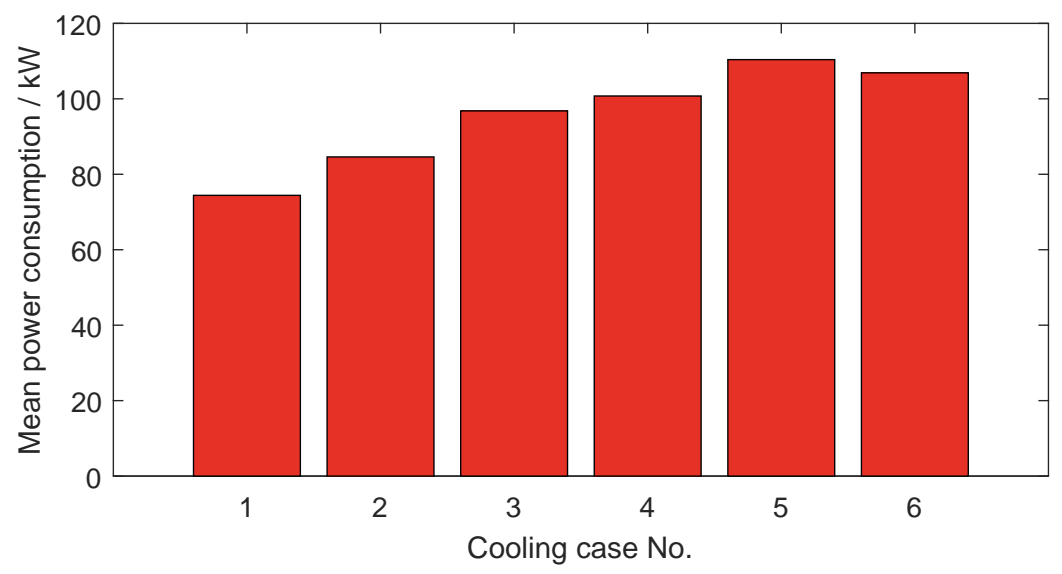

Figure 8: Mean power consumption per operation mode

\subsection{Impact on electricity demand}

The selection of an operation mode by the building can be defined by freely selectable conditions. The hierarchy, in which modes are selected, can be developed with different targets in minds. In our case study, the mode hierarchy was developed under the aspect of the most exergetically preferable operation of the building. Modes can also be selected at any given time by overriding the systems automatic decision. This enables the building energy system to react to certain environment changes and outside signals. In doing so, the building can offer services to other systems, i.e. demand side management.

Every operation mode uses a different combination of devices to fulfil the buildings energy demand. Since the devices have different primary energy sources, the resulting distribution of primary energy consumption for a given demand is different based on the selected operation system. The obvious example is substituting the heat generation by the heat pump, which consumes electricity, with the condensing boiler, which consumes natural gas, thus reducing the building impact on the electric grid.

Figure 8 shows the impact of the operation modes on the mean real power consumption. Due to the fact that in heating mode, electric consumption can easily be shifted by using the CHP or boiler, we consider only the cooling cases here. The electrical power consumption is measured for the whole building and averaged over all weekdays between the 1st July 2014 and 1st 
July 2015. Since not every mode is used in every ambient condition (see Figure 6 , we cannot clearly rule out the influence of other systems like the façade ventilation units. However, the power of the heat pump is large compared to the normal loads of the building. Because the heat pump is often in intermittent operation, we consider the influence of the actual building load to be small, because the downtimes are not included in the consumption calculation. Figure 8 shows an overall increase of electric power consumption for modes lower in the hierarchy. This is reasonable, because the modes are ordered by exergy destruction and for cooling application electric power is the main source of exergy. There is only a small difference between modes 3 and 4 and 5 and 6 , because the operation of the glycol cooler does not consume a large amount of power, as seen in mode 1 , where power consumption is the lowest.

The use of the geothermal field is generally suited to reduce electric consumption. In a demand site scenario the geothermal field can be used as a backup to normal operation and can be used when electric demand should be lowered. The downside of this would be higher overall electricity consumption, because of the high storage inertia the field cannot be used for temporal load shifting.

\section{Conclusion}

In this paper, a mode-based control strategy was introduced as a tool to handle complex building energy systems. A high-level mode selection is made based upon the potential in the heat and cold storage. The introduced, generalized method can be used to design controls for other buildings. The method was applied in a case study to the E.ON Energy Research Center and evaluated by the gathered operation data.

The result of the work is a work-flow for the development of a modebased control strategy as well the real control strategy for the E.ON Energy Research Center itself. Furthermore we were able to show that the analysis of the storage systems can reduce the need for expansive volumetric flow measurement and thus enable to integrate classically controlled heat pump systems into a mode-based control strategy. For a lot of load and ambient conditions, the use of active heat displacement by the heat pump leads to an energy efficient operation. It is also noticeable that a mode-based control strategy is a way to enable the integration of renewable energies into the built 
environment. We demonstrated this by integrating the geothermal field into the building operation.

The use of operation modes for demand response applications is the focus of currently ongoing and future research activities. We showed there is a connection between the active operation mode and mean electric demand, which we can use for demand response purposes. We will extend the buildings systems with an electrical storage battery. From the new system setup we will then derive new operation modes and an electric focused mode hierarchy and test the building operation in a district scenario.

We believe that the mode-based control strategy will enable the building to operate robustly and efficiently and participate in active demand site management.

\section{Acknowledgements}

This paper was presented at the ECOS 2016 conference in Portoroz, Slovenia. We like to acknowledge the financial support of the German Federal Ministry of Economics and Technology, and of the European Unionprecisely: German Federal Ministry of Economics and Technology funded project exergetically optimized HVAC control with dynamic and flexible integration of a monitored geothermal borehole heat exchanger field (03ET1022A) and the EU funded project Energy local storage advanced system - ELSA (EU H2020 Grant Agreement Number 646125).

\section{References}

[1] C. Molitor, D. Cali, R. Streblow, F. Ponci, D. Müller und A. Monti, New energy concepts and related information technologies: Dual Demand Side Management, in Innovative Smart Grid Technologies, Washington, D.C., USA, 2012.

[2] J.D. Spitler, Ground-Source Heat Pump System Research - Past, Present, and Future, HVAC \& R Research, 11 (2005), pp. 165167

[3] L. Lubis, M. Kanoglu, I. Dincer, M. Rosen, Thermodynamic analysis of a hybrid geothermal heat pump system, Geothermics, Volume 40, Issue 3, September 2011, Pages 233238 
[4] R. Fan, Y. Gao, L. Huac, X. Deng, J. Shi, Thermal performance and operation strategy optimization for a practical hybrid ground-source heatpump system, Energy and Buildings, Volume 78, August 2014, Pages 238247

[5] P. Byrne, J. Miriel, Y. Lnat, Design and simulation of a heat pump for simultaneous heating and cooling using HFC or CO2 as a working fluid, International Journal of Refrigeration, Elsevier, 2009, 32 (7), pp.17111723.

[6] C. Yavuzturk, J.D. Spitler, Comparative study of operating and control strategies for hybrid ground-source heat pump systems using a short time step simulation model, ASHRAE Transactions, 106 (2000), pp. 192209

[7] J. Thornton, A Detailed TRNSYS Analysis of Building 137; Oceana Naval Air Station, Virginia Beach, Virginia. Project report for Oak Ridge National Laboratory, 2000

[8] Z. Sagia, C. Rakopoulos, E. Kakaras, Cooling dominated hybrid ground source heat pump system application, Applied Energy, 94 (2012), pp. 4147

[9] H. Park, J.S. Lee, W. Kim, Y. Kim, Performance optimization of a hybrid ground source heat pump with the parallel configuration of ground heat exchanger and a supplemental heat rejecter, Int J Refrig, 35 (2012), pp. 15371546

[10] J. Lee, H. Park, Y. Kim, Transient performance characteristics of a hybrid ground-source heat pump in the cooling mode, Applied Energy, Volume 123, 15 June 2014, Pages 121-128

[11] J. Fütterer, A. Constantin, M. Schmidt, R. Streblow, D. Müller und A. Kosmatopoulos, A multifunctional demonstration bench for advanced control research in buildings-Monitoring, control, and interface system, in IECON 2013 - 39th Annual Conference of the IEEE, 2013.

[12] J. Fütterer und A. Constantin, Energy concept for the E.ON ERC main building, E.ON Energy Research, Bd. 4, Nr. 9, 2012. 
[13] J. Fütterer, A. Constantin, M. Schmidt, R. Streblow und D. Müller, Monitoring technique, evaluation methodology and results for a multifunctional building with geothermal energy, in CISBAT 2013 Proceedings Vol. II - Cleantech for Smart Cities and Buildings,, Lausanne, Switzerland, 2013.

[14] S. Pourzeynali, H. Lavasani und A. Modarayi, Active control of high rise building structures using fuzzy logic and genetic algorithms, Engineering Structures, Bd. 29, Nr. 3, pp. 346-357, 2007.

[15] V. Rath, A. Wolf und M. Bücker, Joint three-dimensional inversion of coupled groundwater flow and heat transfer based on automatic differentiation: sensitivity calculation, verification, and synthetic examples, Geopysical Journal International, Nr. 167, pp. 453-446, 2006. 